\title{
Policy Challenges and Impact of Global Rankings, Accreditations in Transforming University Systems to Value Creation Centres
}

\author{
Jayant Kumar Panigrahi, Pragyan Ranjan Gharai, Biswajit Das, Ipseeta Satpathy
}

\begin{abstract}
Dynamics in the higher education, internalisation and global economic turmoil drastically influences the research outcomes with implications to the global ranking of higher education institutions (HEIs) and the universities. National education policies and the ranking of higher education institutions (HEIs) are entwined and mutually influence each other. In recent times, the global ranking by various organisations like QS, THE, and government agencies become proxy to conclude the excellence of a university. National Global, regional and national socio-economic-political concerns are influencing the functioning of universities with respect to international student recruitments. International student admissions also greatly contribute to the funds for the university and economy of the nations, simultaneously. This research paper is an investigative study of value creation in the university education systems and the impact of ranking and higher education policies.

In this paper, authors have highlighted a couple of key points. First of all, the universities have to acclimatize as per the global rankings standards and reinforce to become value creation centers, with more responsible towards the demands of society. The authors have highlighted about the convolution and challenges universities are facing and measures to deal with. The conscientious approach to the facades of new knowledge areas in the new global socio-economic milieu gives a tangible and relevance to the execution of responsible research and innovation with value co-creation in university systems.

Index Terms: university systems, HEIs, RRI, global ranking, education policy, value co-creation
\end{abstract}

\section{INTRODUCTION}

Universities are likely to be questioning, experimenting, sprouting with openness to conclude that 'nothing-is-impossible'. They are also the universes of learning, endeavour new ideas, assorted thoughts, and dialogue on topics based out of new theories, cavernous thinking, research and data. One of the imperative functions of the university is research frameworks, patents, publications projects, consulting, new technologies, knowledge transfer delivered on the campus. The intangible stuffs produced by the university are to satisfy the requirement of the economies and the society. Numerous

Revised Manuscript Received on November 11, 2019.

Jayant Kumar Panigrahi, ICER, New Delhi, India

Pragyan Ranjan Gharai, KIIT School of Management, KIIT University, Bhubaneswar, India

Biswajit Das, KIIT School of Management, KIIT University, Bhubaneswar, India

Ipseeta Satpathy, KIIT School of Management, KIIT University, Bhubaneswar, India universities are perceived to be more specialised based on the performance in specific sphere and strengths.

Universities have principally four natural dimensions like preparing students for employable, knowledge transfer to industry/business, evolving solutions to problem and serving the society. Although the university is considered as a system as per systems theory, the basic purposes of the university is creating better human values. The desire is to get better key supplies like students, teachers, staff and the funds essential for optimal performance of the university. This technique is apparent from the Triple Helix Model (Etzkowitz, 2002) and Interdependence Model (Stevens \& Bagby, 2001). These models guide to studies and other models for university-industry relationship. Simulating Knowledge Dynamics in Innovation Networks (SKIN) model makes an attempt to enhance our knowledge about the complicated practices in recent innovative research by scholars to stumble on solutions to complicated challenges.

Value creation in the university systems and the perception by peers swerve as per the value of supply inputs. Findings in research indicate that parameters used by ranking and accreditations authorities or agencies insist on universities to focus on the value creation inside the system and improving continuously. The findings stress on collaboration with researchers, educators and experts to authorize universities for meaningful contribution towards practical, functional societal issues and elevate the interest of scholars and the industry. A holistic approach is could do with the trans-disciplinary and inter-disciplinary curriculum in the university that tackle the gap between education-research-business and co-create values. Accomplishing the purpose in the evolving structures, cultures of the university system requires the pressures of change being exercised by altering the larger goals.

\section{Impact of Global Rankings}

In the $21^{\text {st }}$ century, the world is inundated with the list of ranking and comparisons along with copious proportions. Some of these are based on irrefutable facts whereas few are also vague and prejudiced in their estimations. Subsequently, it is imperative to hold few perspectives when interpreting the ranking lists. Countries are accorded human development rankings, their knowledge economy, levels of global competitiveness, alleged levels of corruption etc.

The outburst of university rankings also indicate that we tend to exist and compete in a 
ranked world. It looks like unavoidable that universities subject themselves to comparative analytics, rankings for competitive advantage. Yet, institutions being a part of multifarious systems, it appears to be inevitable that rankings of universities is nothing but vitriolic.

Inevitably, use of benchmarking to weigh against nations, economies, passports etc., make things easier whereas they are intricate and dynamic in reality. With regards to universities, the pressure of comparisons infringes individual preferences to policies of countries, priorities, and even to the competitiveness. Therefore, the issue appears about whether universities need to be compared and ranked, or the methodologies adopted.

Institutions around the world that may not emerge in top list of universities by rankings but they continue their quest of educating and developing human capital and developing the society, aligned to sustainable development goals. Obsession about ascending in the league chart disregards the larger responsibility and purpose of vigorous education institutions.

Arguments of critics are that rankings portray universities interest away from teaching and social responsibility. It is believed that rankings support the advantages, the top 200 ranked institutions have. These institutions are old and established in the midst of more than 25,000 students, $2,500+$ faculty members, with huge endowments and annual budgets. There is a diversion from the focal point of rankings that emphasise quality and not about the process followed. Both are reasonable issues. Frequently, the usages of ranking are criticised. Reckless use of rankings is a matter of huge concern, whereas the antidote to this predicament is to bring in more public education institutions but not to impede of rankings.

Other disparagement of conducting rankings is that they endorse building world-class institutions instead of building world-class education systems. This is one of the most critical issues of impact of rankings. This is also tricky to visualize the likelihood of having the world-class higher education systems with no world-class HEIs. Therefore the right question for the wrong reasons is the superficial separation between the two.

Finally, as rankings have an impact on generating funds and collaborations, there is a vicious inducement for universities to blow up their data to scale up the ladder of rankings, each year. Authenticating the validity of data shared by universities to ranking agencies is the key challenge that needs to be considered for transparency in ranking information systems.

\section{Ranking of Universities and Higher Education Institutions}

Academicians, researchers and experts were asked to answer the question on - How to create a more rational methodology to gauge the research conducted and patented in universities? University rankings are increasingly getting popular across the globe and at a regional level. Currently, all countries and regions have some kind of the ranking systems driven by accreditation agencies or research and commercial organisations, or the media. In India, the NIRF ranking system is operational for the last 3 years. Rankings are done with data collections on various parameters of the education system and used for specific and different purposes.

Rankings focus only in the top 200, out of approximately thousands of universities globally. Countries believe them as a dimension of their nation's aspirations and potency. Universities exploit the ranks to outline performance goals and implement marketing actions. Educators exploit the rankings to uphold their certified status; the rankings give the students and parents to choose their prospective institution to study or research. Other stakeholders like Industry and funding agencies also use rankings to guide their judgments regarding collaborations and funding apportionments.

Prospective students have their specific needs, looking for evidence on a specific discipline of study, fee structure, employment prospects etc. associated with the HEIs of their choice based on rankings. A university that may be well-known for one or two disciplines may not be outstanding in all offered disciplines. Ascertaining further specifically, based on research conducted and disseminated can be a better way. Therefore, the ranking of universities may not be the most accurate technique to ascertain. We need to design multidimensional methodologies that will adapt to the complex nature of academic research of our universities.

\section{THE DIFFERENTIATION PERSPECTIVE}

The focal perspective on the evolution of tertiary education systems in the last decades has been important for addressing growth, internalisation and importance of innovation within the economy and society.

Among the various categories of HEIs, numerous structures of differentiation between teaching and research were determined, that disagree with the old standards of teaching and research. With the increasing importance of research for responsible innovation has distinguished completely different knowledge areas and knowledge creation. The principal course of applied research towards industrial development indicates the differentiation of diverse research purposes, followed by the importance of knowledge transfers, and patents for higher education institutions.

Other point of view came up with the beginning of the knowledge-based economy, with the new stress on vital role of higher education for progression of responsible research and innovation (RRI). The contribution to the national economy has been devised in addition to the earlier missions of teaching and research in higher education institutions.

\section{University Value Chain Model}

The value chain model developed by Khaled Abed Hutaibat's (2011) broadly elucidate the value chain in the 
higher education institutions and can be applied to the university systems. It is apparent that the approach in the model identifies 3 broad areas: perception of academic quality, research and teaching activities. Perception of academic quality includes the strength of the global academics. It also refer to topics such as the stiffness of financials, grants/funds, tension connecting teaching with research and continuous development of course curriculum as per evolving industry requirements. Research and teaching are the core operational activities and foremost strategic functions of universities. Teaching includes the actual classroom delivery/interactions but also the care outside the class room.

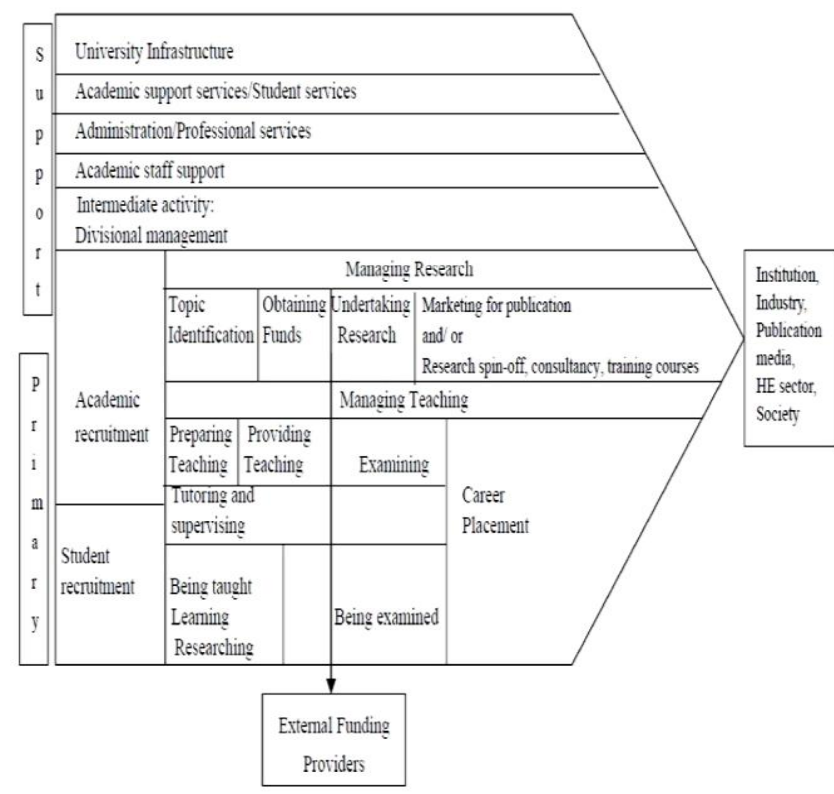

Fig 1: University Value Chain

Source: Khaled Abed Hutaibat, (2011, p. 218)

\section{Knowledge Triangle Model}

One of the growth drivers of the economy is higher education which is also a vital element of the knowledge triangle. The significance and quality of researches undertaken in universities is a critical indicator of the education system. The idea of research is extending from curiosity-driven to user-benefits. The model of the knowledge triangle (KT) focuses on the value of the three-way interrelations among elements, and on possible approaches to their amalgamation.

Fig. 2: Knowledge Triangle Models

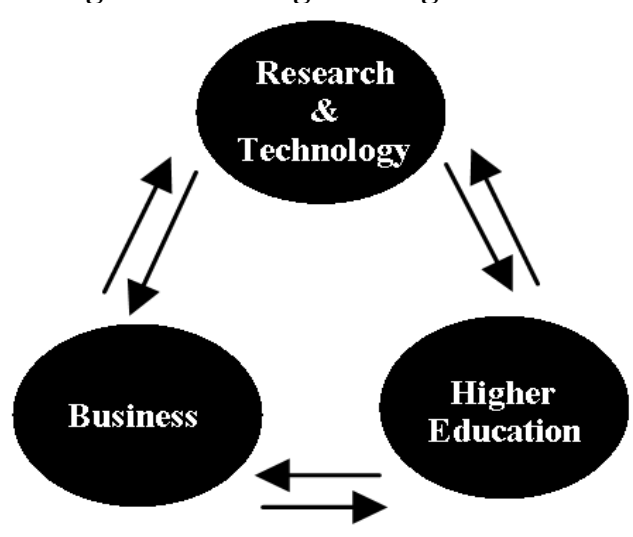

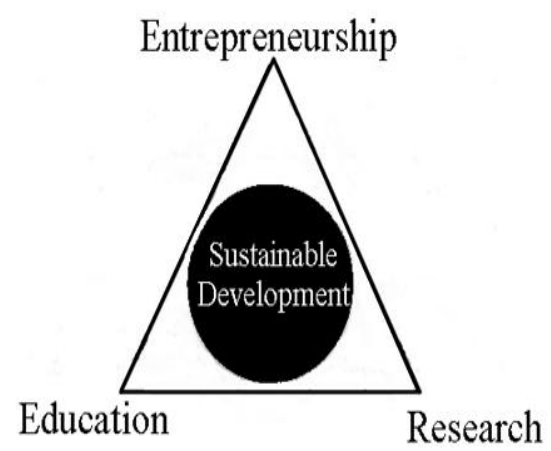

Source: Authors development

The knowledge triangle mentions about interlink between education, research, innovation, three fundamental drivers the knowledge-based economy. In recent times, several models were emerged to demonstrate the practice of knowledge/value creation and its relevance through innovation. Nonetheless, the models share several inferences about the non-linear nature of innovation. Also, new knowledge is the source of innovation and new developments for innovation points towards new possibilities for research. This procedure is captured by the conception of the knowledge triangle model that highlights the encouraging benefits to be derived from strong links.

\section{Impact of Policy Challenges}

Here we are able to outline few main policy challenges that have to strengthen by the recent trends in supremacy of higher education towards enhanced autonomy of the HEIs. Primarily we are able to depict the characteristic of 2 layers of polices towards the knowledge-triangle. The foremost layer should result in changes of the structures along with activities with processes in the creation of recent forms of HEIs. The secondary layer focuses a lot on the interrelations of institutions with their milieu. The major policy challenges are seen in relation to the probability of influencing the autonomous institutes by different regulatory policies. Influencing the autonomous institutions might mean to the engage 3 components of the knowledge triangle, through review of each one. Policies measure the goals, standards, missions of institutions towards assessment and evaluation of governance structures.

The issue at this level concerns the prominence that ought to be set policy guidelines, relating to the Intellectual Property Rights (IPR), knowledge transfer, funding opportunities and policies about. Internships, employment, support for start-ups. The innovation systems connecting dots in the triple helix model of university-industry-government relations has diverse views towards recently developed to the quadruple and quintuple helix models. The colossal diversity of the higher education sector in several regions and countries is setting the firm conditions for policies, that generalise -'one size fits all' policies across these various spectrums.

In this paper, we propose a hierarchical approach with the multi-way interdependence of education - research, research - innovation, and education - innovation. From the literature reviews, we found several debates about how the performance can be influenced, and how certain structures

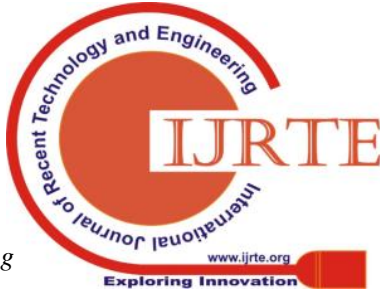


might manipulate the performance in the system.

\section{- Identifying Internal Value Chain}

Higher education institutions ought to find out distinctive activities for co-creation of value in diverse modes. All these activities have specifically varied costs, cost drivers. Institutions should take a broad outlook on the unique value chain activities in the system. To understand the broader view, institutions should categorize value chain activities as procedural, structural and operational.

Procedural activities, like quality management which permeate all facets of operations and reveal the capability of the institution to achieve efficiency. Structurally, the numbers of campuses establish the basic economics of the institution. And operational activities, like making decisions about new course curriculum, delivery plans, and teaching are also the regular activities of the education institutions.

Generally, cost management functions focus more on operational actions which have unit and batch determined costs. Because, institutions usually tend to control operational costs, therefore, it is imperative to classify and focus management consideration towards the procedural cost drivers that represent the long term strategic goal of institutions. This builds the foundation of an institution's competitive advantage.

\section{- Determining the Strategic Activities of value creation}

To resolve strategic links of the value chain, higher education institutions should instigate to identify the features of its services that are weighed, perceived by the stakeholders and the features that they should built up to create value in the future. The features might embrace quality, suitable to specific needs and all tangible or intangible offerings of the institutions. Identifying important activities in the value chain provide a competitive advantage. Some universities seek to achieve competitive advantage by fulfilling the needs of students by integrating suitable modifications in developing new curriculum as per the evolving need of the business/ industry, providing flexible learning systems for courses and delivery as well as support services. Thus, these actions are deemed as strategic in the university systems.

The function of research activities in a university remains a debatable issue while differentiating amid strategic and non-strategic activities. Institutions also need to identify non-strategic activities. The quests of novel knowledge all the way through research are decisive and characterize features for top universities. Research activities are expensive and time consuming. Even though the strong belief is that research augments the excellence of teaching, research is frequently associated with a de-emphasis on the quality of teaching.

\section{- Analysing the Costs to Activities for Value creation}

With the identification of the value chain in the system, the operating costs, revenues, and assets are allocated. Every activity has costs which generate revenues and manage assets for value addition in the system. Techniques developed in the course of allotting costs to the right value creation are action based costing
Identification of the value chain activities that cost drive cost may be an approach to understanding the cost and categorising into strategic and non-strategic activities. On the other hand, institutions should understand the value chain framework as a whole. It is necessary to acknowledge that, the volume is not the only realistic approach to justify cost behaviour.

\section{- Improving Value Chain Analysis}

Institutions accomplish the aggressive competition by analysing and sustaining the value chain than the peers. Management of value chain means to boost the quality of services for competitive advantage. An Institution craving to outperform its peers needs to differentiate through higher quality deliveries in the value chain.

\section{Challenges in Analysing Value Chain in Education Systems}

Analysing the value chain is a foremost contrivance for strategic management and has numerous challenges. The conventional accounting methods were not intended to categorize costs with value creation activities. Amid use of information technology systems, the cost classification dilemmas can be resolved. Higher education institutions with complex value chains make the analysis more challenging. Sensing the opportunities, for-profit universities, target working professionals for online or weekend classroom programs. In addition, online platforms also offer education courses along with certification, in association with HEIs. Value additions are significant in enabling and competing with conventional educational institutions. Public universities need to satiate regulatory authorities, funding authorities and other stakeholders for its effectiveness and creation of value. The analysis is also used for determining at what point values are added in the value chain of the institution. All Institutions need to develop their resources and utilize effectively. Therefore analysing value chain is an important framework to aid these needs.

\section{CONCLUSION}

The outburst of significance in rankings is been transcended by the degree of criticism virtually from academics, policy-makers, development agencies, funding agencies and students. On positive note, rankings deal with the information on the feature of higher education institutions. The demand is significantly increased by the necessity to craft informed options of universities, in a milieu of massification and assortment of education providers. Students and parents use the rankings to have a preference where to study. Patrons and alumni draw on rankings to ascertain the best institute for their endowments in an attempt to apprehend the best prospective value for their funds. Whilst identifying collaborations, industry and business incubators etc. rankings and ranking parameters assist for taking decisions about the most capable partner institutions.

Furthermore Governments frequently use rankings to weigh the institutions and their global competitiveness. The criticism to abolish rankings advocates that the process of ranking encourage putting up global universities, not the

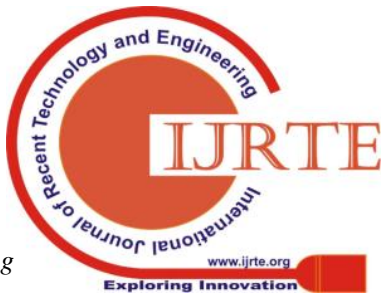


education systems. Critics never suggest 'how nations can accomplish and uphold the world class tag of their institutions boosting up the education system aligning with sustainable development goals'?

This empirical study concludes that the need for transforming Universities to value creation centers for the society. They should be the true centers of Scientifically Oriented Knowledge and Wisdom for the benefit of mankind. Catalysing innovation through the integration of the knowledge triangle model is incontrovertibly the logical continuance of the mutual efforts of the relevant stakeholders. Its suitable implementation is deliberated and in the process of refinement. The indubitable value creation by the university as an active player can be seen in today's rapidly evolving world.

\section{REFERENCES}

1. Ahrweiler, P., Pyka, A. \& Gilbert, N. (2011) A New Model for University-Industry Links in Knowledge based economies. Journal of Production Innovation Management, 28, 218-235.

2. Hutaibat, KA (2011). Value Chain for Strategic Management Accounting in Higher Education, International Journal of Business and Management, Vol. 6, No. 11, pp. 206-218

3. Sarmah, C. K., \& Hazarika, J. (2015). Educational Gender Gap in Assam: A Statistical Analysis. BEST: International Journal of Humanities, Arts, Medicine and Sciences, 3(11), 125-129.

4. Banerjee, S., Wahl, M.F. and Panigrahi, J.K. (2018) Technology, Innovation and Knowledge Transfer: a Value Chain perspective, International Journal of Mechanical Engineering and Technology. 9(1), pp. $1145-1161$

5. Cooper, R., \& Kaplan, R. S. (1992, September). Activity-based systems: Measuring the costs of resource usage. Accounting Horizons, 1-13.

6. Jackson, N., \& Lund, H. (2000). Benchmarking for higher education. Milton Keynes: Open University Press.

7. Donelan, J. G., \& Kaplan, E. A. (1998, March-April), Value chain analysis: A strategic approach to cost management. Journal of Cost Management, 7-15.

8. Etzkowitz, H. (2002). The triple helix of university-industry-government: Implications for policy and evaluation Report 2002:11. Stockholm: SISTER Swedish Institute for Studies in Educations.

9. Sumadsad, C., \& Tuazon, A. (2016). Gender and Development (GAD) Awareness in a Higher Education Institution. International Journal of Educational Science and Research (IJESR), 6(3).

10. Filippetti, A. and Savona, M. (2017) University - industry linkages and academic engagements: individual behaviours and firms' barriers. Introduction to the special section. Journal of Technology Transfer, 42 (4). pp. 719-729.

11. Gharai, P.R., Panigrahi, J.K., Satpathy,I. And Das,B. (2019) Value Creation through Agile Social Entrepreneurs toward Sustainable Development for Generation Next: A Unified Empirical Case Analysis, International Journal of Public Sector Performance Management. (in press)

12. Gilbert, A. D. (2001). The idea of a university: Enterprise or academy. Manning Clark Symposium. Retrieved December 18, 2003, from http://www.unimelb.edu.au/vc/present/manning clark.pdf

13. Hattie, J., \& Marsh, H. W. (2002). The relationship between research and teaching: A meta-analysis. Review of Educational Research, 66(4), 507-542.

14. Ouada Jamoussi, H. B., \& Makhlouf, E. M. (2018). School Performance and the Education Systems' Efficiency: An International Comparison Based on OECD PISA Surveys. International Journal of Human Resources Management (IJHRM) ISSN (P), 2319-4936.

15. Hewitt-dundas, N. (2012) Research intensity and knowledge transfer activity in UK universities, Research Policy, 41:2, 262-275

16. Hazelkorn, E. (2008) Globalisation, Internationalisation and Rankings, International Higher Education, No. 53, 8-10

17. Aiyer, M., Panigrahi, J.K., Das, B. and Neurgaonkar, S. (2019) Cross-Functional Process Framework for Customer Experience and Customer Relationship Management: Reinventing a Dimension Mix to Value Co-creation. Journal of Advanced Research in Dynamical and Control Systems 10(9), 2545- 2550.

18. Hughes, A. (2010) The Multi-faceted Role of Universities. ESRC Society Now, summer -2010 Issue 7, In Focus: p. 8 .

19. Jackson, G. B. (2000). University of Phoenix: A new model for tertiary education in developing countries? TechKnowLogia, 2(1), 34-37.
20. Katz, Y. (2017). Social Media Is Powerful, but Can It Change Policies of Institutionalized Organizations Such as the Israeli Army?. International Journal of Humanities and Social Sciences (IJHSS), 6(6), 29-34.

21. Lusch, R. F., Vargo, S. L. \& Tanniru, M. (2010) Service, value networks and learning. Journal of the Academy of Marketing Science, 38, 19-31.

22. Panigrahi, J. K., Tripathy, S. and Das, B. (2017) Thematic analysis of service innovation taxonomy within supply network, creating value for the system. International Journal of Mechanical Engineering \& Technology, Volume: 8(9), Pages: 57- 69.

23. Pister, K. (1999). The University of the Future: Place, process or paradigm. In J. Brennan, J. Fedrowitz, M. Huber, \& T. Shah (Eds.), what kind of university? International perspectives on knowledge, participation and governance (pp. 229-239). Buckingham, UK: SRHE and Open University Press.

24. Porter, M. (1980). Competitive strategy. New York: The Free Press.

25. Moses, C., Akinbode, M., Olokundun, A. M., \& Agboola, M. G. (2015). Entrepreneurship education and action-oriented pedagogical approaches. International Journal of Educational Science and Research, 5(5), 53-60.

26. Porter, M. (1985). Competitive advantage: Creating and sustaining superior performance. New York: The Free Press.

27. Valentin, E. (2000) University-Industry cooperation: a framework of benefits and obstacles. Industry \& Higher Education, 14,165-172

28. Walshok, M.L. (2005) The transformative role of universities in a Knowledge Society. Industry and Higher Education,19,209-215 